\title{
A educação superior no Brasil e a proposta de liberalização do GATS
}

\author{
Paula Santos de Abreu'
}

\section{Resumo}

Devido à grande atratividade do mercado internacional de educação, a iniciativa da liberalização promovida pelo GATS, o Acordo sobre Serviços da OMC, já é uma realidade. No entanto, há grande resistência de alguns países que consideram a educação como um bem-público e que deve ser regulado pelo Estado. Consoante com esse entendimento encontra-se o da Academia que acredita que o papel da educação é de suma importância para promover os propósitos sociais inerentes à construção de uma Nação que não pode ficar à mercê das regras do mercado. Sendo assim, necessário se faz discutir os meios de se alcançar um desenvolvimento sustentável mediante novas formas de cooperação internacional que não se tornem instrumentos de exclusão social. O texto aborda alguns pontos relevantes a serem observados quando da abertura desse mercado.

Palavras-chave: Liberalização. Comércio. Educação. Desenvolvimento sustentável. GATS.

\section{Introdução}

Enquanto muito se fala da qualidade da educação no Brasil ou da falta dela, muito se exalta o elevado padrão de qualidade do ensino nos países industrializados. Há também uma percepção fundada de que a alta qualidade da educação está intimamente ligada ao grande desenvolvimento tecnológico alcançado nos países do primeiro mundo e que o conhecimento tecnológico é um

\footnotetext{
${ }^{1}$ Advogada. Mestre em Direito das Relações Internacionais pelo Centro Universitário de Brasília (UniCEUB). Pós-graduada em marketing pelo COPPEAD- UFRJ e gerente de desenvolvimento de mercado da Embaixada do Reino Unido. Foi coordenadora do Núcleo de Integração para Exportação (NIEx) da Secretaria de Relações Internacionais do Agronegócio (SRI) do Ministério da Agricultura, Pecuária e Abastecimento. Professora de Direito Internacional Público e Privado. E-mail: paula_abreu@yahoo.com
} 
dos grandes responsáveis pela alta qualidade de vida dos Estados onde o nível de industrialização é maior.

Sendo assim, seria possível inferir que ter instituições de ensino estrangeiras (de países desenvolvedores de tecnologia) escolhendo "o quê" aprender e "como" aprender poderia uma alternativa de transferência de conhecimento e, consequentemente, de fomentar o desenvolvimento? Quais os pontos positivos e negativos da liberalização do setor de educação no Brasil? O que fazer para proteger interesses estratégicos da nação?

Este artigo visa a abordar alguns argumentos para reflexão sobre essas questões. Para isso, é preciso primeiro identificar o contexto da internacionalização dos serviços de educação, sobretudo após a ascensão da Organização Mundial do Comércio para, em seguida, analisar a posição de alguns países quanto ao papel da educação em suas políticas públicas. Mais adiante, serão discutidos alguns aspectos importantes que devem ser levados em consideração para que se possa tirar maior proveito da liberalização do setor educacional, principalmente o de Educação Superior, uma nova realidade que se descortina a nossa frente.

\section{0 contexto da internacionalização}

Atualmente, há um reconhecimento generalizado de que o comércio internacional de serviços ${ }^{2}$ desempenha papel central para a balança comercial de grande número de países e há sólidas razões para se acreditar na continuidade da expansão desse mercado. Entre 2000 e 2007, cresceu a uma taxa média anual de $8,6 \%$, muito acima da média mundial. O fluxo mundial de serviços, em 2007, totalizou US\$2,9 trilhões, o que representa 23,1\% do comércio mundial de bens (BRASIL, 2008), percentagem que cresce a cada ano.

No Brasil a atividade terciária é também significante. Em 2007, o faturamento global do setor de serviços representou 65,8\% do PIB nacional e mais de 50\% de empregos formais no País, segundo o IBGE. Dados do Banco Central indicam que

\footnotetext{
${ }^{2}$ Em nosso ordenamento jurídico, entende-se por serviço "qualquer atividade fornecida no mercado de consumo, mediante remuneração, inclusive as de natureza bancária, financeira, de crédito e securitária, salvo as decorrentes das relações de caráter trabalhista." Art. $3^{\circ}$ $\S 2^{\circ} \mathrm{CDC}$.
} 
o setor de serviços é o principal receptor de investimentos estrangeiros no País. Em 2007, foi responsável por $46,9 \%$ do total desses investimentos contra $39,3 \%$ no setor secundário e $13,8 \%$ no setor primário.

Com um mercado internacional tão atrativo a investimentos estrangeiros, era necessário que os Estados estipulassem regras para sua abertura, inclusive utilizando esse setor como moeda de troca para seus produtos. Durante a Rodada do Uruguai conduzida no âmbito da OMC, o Acordo sobre Serviços - o GATS - foi um dos acordos mais polêmicos e esperados. A liberalização do mercado de serviços internacional se deu com a submissão das Listas de Compromissos de cada país, que estabelece qual setor, o prazo e as condições para a abertura deste mercado. Resumidamente, o GATS foi então negociado para regular os tipos de medida que a OMC deve aplicar para o comércio de serviços referente a não discriminação (tratamento $\mathrm{NMF}^{3}$ ), transparência, e regulamentação doméstica.

Os segmentos de serviços ${ }^{4}$ foram divididos em três blocos: a) os serviços domésticos, como hotelaria, restaurantes e serviços pessoais - não sujeitos à regulação internacional; b) setores como transportes e telecomunicações - vistos como domínios clássicos da atividade ou monopólio estatal dada sua importância infraestrutural; c) um terceiro bloco de serviços relevantes, incluindo educação,

\footnotetext{
${ }^{3}$ Princípio da Nação mais favorecida

${ }^{4}$ A definição de serviços para o GATS é feita classificando-os quanto à sua prestação.

São os chamados Modos 1 a 4. São eles:

Modo 1 - Prestações transfronteiriças (Cross border supply)

São os serviços prestados por uma empresa em um país a um consumidor em outro país. Consiste no movimento do produto do serviço através da fronteira. São os serviços transmitidos por rede de telecomunicações, transporte. Um exemplo seriam os cursos à distância via internet ou teleconferências.

Modo 2 - Consumo no Exterior (Consumption Abroad)

São aqueles prestados com o movimento do consumidor através da fronteira, tais como: turismo, educação, serviços médicos, isto é, são os serviços consumidos no exterior.

Modo 3 - Presença Comercial (Commercial presence)

São aqueles cuja presença comercial do prestador do serviço é necessária. Há investimento direto para a prestação do serviço. Alguns exemplos são os cursos presenciais com a Instalação de universidades ou faculdades no país.

Modo 4 - Presença de Pessoas Físicas (Presence of natural persons)

Neste caso, há movimento temporário da pessoa física que presta o serviço, como professores, consultores, administradores. Tem relação direta com as regras de imigração de cada país, já que o país importador deve emitir vistos que permitam a entrada do profissional, para atender o cliente.
} 
seguros e saúde - considerados em vários países, serviços de responsabilidade governamental, dada sua importância para integração social e coesão regional e com necessidade de grande regulação, não podendo ser deixados à mercê da regulação dos mercados 5 .

Mesmo diante desse posicionamento, durante a Rodada de Doha, entre 2000 e 2005, os Estados Unidos, seguidos pelo Japão, pela Austrália e pela Nova Zelândia, apresentaram propostas para a liberalização do mercado de educação superior internacional. Tal fato é compreensível; pois, desde o início dos anos 90, cerca de 1,5 milhão de estudantes universitários estavam matriculados no Exterior e em 1995, o mercado global para o ensino superior era estimado em 27 bilhões de dólares.

Segundo dados da OMC, nos anos 90, os Estados Unidos, eram os maiores exportadores de serviços de educação ${ }^{6}$, mas começavam a enfrentar concorrência, principalmente de Estados europeus, da Austrália, do Canadá e do Japão. Em 1994, antes de adotar uma posição bastante agressiva no setor, a Austrália já contava com 70 mil estudantes estrangeiros, na maioria asiáticos, que contribuíam com dois bilhões de dólares australianos anuais para a economia do país?

Apesar dos esforços desses países, de 192 Estados signatários do GATS, apenas quatro se comprometeram a abrir o setor de Educação para concorrência

\footnotetext{
${ }^{5}$ Cf. GATS, 2008.

${ }^{6}$ No início dos anos 90 deu início à multiplicação de campus deslocalizados (local branch campuses) ou de campus subsidiários. Alguns exemplos são o do MIT, que decidiu estabelecer uma escola de engenharia na Malásia e da Open University do Reino Unido que se preparava para firmar acordo com a Florida State University a fim de ampliar sua ação nos Estados Unidos e, em parceria com seu sócio norte-americano, atingir estudantes em outros países.

${ }^{7}$ Esses números se referem apenas aos cursos presenciais não se contabilizando os cursos ministrados por internet, por sistemas de franquia ou por outros meios de ensino a distância. Tampouco se incluem a formação dada por instituições corporativas.
} 
estrangeira $^{8}$. O entendimento que a Educação Superior é um serviço e, consequentemente, um grande mercado a ser explorado por empresas privadas internacionais, não encontra respaldo no próprio meio acadêmico, uma vez que muitos acreditam que o que está envolvido é tão soberanamente importante que a abertura seria uma "ameaça" aos propósitos sociais inerentes à construção de uma Nação. Em outras palavras, o ensino, por suas características intrínsecas, deveria ser tratado de forma diferente nas negociações internacionais de liberalização. Aparentemente, os princípios do GATS de liberdade de concorrência,

\footnotetext{
${ }^{8}$ As barreiras previstas para o acesso ao Mercado de educação são classificadas como restrições de acesso e/ou limitações ao princípio do tratamento nacional. Algumas limitações são resultantes de políticas regulatórias ou outras medidas que dificultam a prestação do serviço por empresas estrangeiras.
}

Barreiras do setor identificadas na proposta Americana - World Trade Organization - S/ CSS/W/23 - 18 Dec. 2000 (00-5552):

a) Proibição de prestação de ensino superior, educação para adultos e educação profissional por Instituições estrangeiras;

b) Falta de oportunidade aos prestadores estrangeiros de educação superior, educação para adultos e educação profissional para obter autorização para estabelecer sede dentro do território do Estado membro;

c) Falta de oportunidade aos prestadores estrangeiros de educação superior, educação para adultos e educação profissional para conferir graus, diplomas e outros títulos;

d) Restrições inapropriadas para transmitir material didático por meio eletrônico;

e) Necessidade de comprovação econômica aos prestadores destes serviços;

f) Medidas que requerem o uso de um parceiro local;

g) Denegação de permissão a fornecedores privados do serviço para entrar e sair de joint-ventures com parceiros locais e não locais voluntariamente;

h) Quando a aprovação governamental é necessária, os atrasos excepcionalmente longos e quando a aprovação é denegada, não apresentar razões para tal medida e nenhuma informação sobre as maneiras de obter aprovação no futuro são fornecidas;

i) Tratamento fiscal que discrimina as Instituições estrangeiras;

j) Os parceiros nacionais de uma joint venture têm prerrogativas sobre os parceiros estrangeiros;

k) Franquias têm tratamento desfavorável em relação a outras formas de negócio;

1) Leis e regulamentos nacionais são obscuros e aplicados de maneira injusta;

m) Subsídios para educação superior, educação para adultos e educação profissional não são oferecidos de maneira clara e transparente;

n) Requisitos mínimos para contratação local são desproporcionalmente altos, levando a custos operacionais altos;

o) Pessoal especializado (incluindo gerentes, especialistas em tecnologia, conferencistas), necessários por curto período de tempo, encontra dificuldade em obter autorização para entrada e permanência no país;

p) Remessa de lucros ao exterior é altamente tributada;

q) Altos impostos/taxas para obtenção de licença ou pagamentos de royalties. 
transparência, igualdade de tratamento e o princípio da nação mais favorecida não deveriam ser aplicados.

A posição de alguns Estados europeus, como a da França, pôde ser claramente entendida na sessão de abertura da Conferência Mundial sobre Educação Superior (CMES) reunida pela UNESCO em 1998 quando o primeiro ministro francês, Lionel Jospin (1998), declarou que rejeitava a concepção mercantil de que o Ensino Superior poderia ser determinado pelo mercado. O Primeiro Ministro declarou que, como todos os europeus, era fiel ao serviço público de educação, portanto ao papel essencial do Estado de garantir a igualdade de oportunidades.

Por sua vez, Céline Saint-Pierre (1998), presidente do Conselho Superior de Educação do Quebec, Canadá, declarou que o ensino superior deveria ser definido como um serviço público e não como uma empresa do saber e de formação orientada pelas leis do mercado.

Também no Brasil, essa posição encontra respaldo. Durante palestra proferida no Seminário Internacionalização da Educação Superior, promovido pela ABMES em Brasília, no dia $1^{\circ}$ de outubro de 2003, Nina Ranieri (2004), secretária geral da Universidade de São Paulo, declarou que a educação, no enfoque dado pela Organização Mundial do Comércio (OMC), fica submetida "aos investimentos especulativos e aos interesses lucrativos que orientam as iniciativas dos investidores no contexto do comércio internacional".

Da mesma forma, em 2004, motivados pelo crescimento do mercado da educação transfronteiriça impulsionado pelo aumento da demanda por educação superior no mundo todo, a diminuição dos investimentos públicos em vários contextos nacionais, a diversificação de instituições oferecendo educação superior e o surgimento de novos métodos de oferta, o American Council on Education (ACE), a Association of Universities and Colleges of Canada (AUCC), o Council for Higher Education Accreditation (CHEA), e a International Association of Universities (IAU) publicaram a declaração, “Sharing Quality Higher Education Across Borders: A Statement on Behalf of Higher Education Institutions Worldwide", sobre a aplicação das regras de comércio internacional ao 
setor de educação9. A Declaração foi taxativa ao estabelecer que as regras do comércio não são apropriadas para lidar com os propósitos acadêmicos de pesquisa ou sociais e culturais da Educação Superior e que a política comercial e a política pública de educação podem ser conflitantes, com a primeira prejudicando a capacidade da Educação Superior a conduzir sua Missão. Acreditam que a aplicação das regras de comércio internacional aos complexos sistemas de Educação Superior Nacionais poderia acarretar consequências prejudiciais à educação, mesmo não sendo intencionais.

Mas será que não há meios de conciliar o interesse da abertura dos mercados com a proteção do direito à educação de qualidade, criando um ambiente favorável à utilização desse instrumento para promover a transferência de tecnologia e consequentemente o desenvolvimento sustentável?

\section{A posição da UNESCO sobre a liberalização dos serviços de educação}

Em 9 de outubro de 1998, na sede da UNESCO em Paris, representantes de mais de 180 países aprovaram a "Declaração Mundial sobre a Educação Superior no Século XXI: Visão e Ação"10. O documento baseia-se completamente no fato de que o acesso à educação, inclusive ao ensino superior, é um direito fundamental, não podendo assim, ser tratado como mercadoria comercial. O entendimento da comunidade internacional é, pois, que a educação superior é um serviço público e deve basear suas orientações de longo prazo em objetivos e necessidades sociais, incluindo o respeito às culturas e à proteção do meio ambiente. Também entendem que não há como assegurar um "desenvolvimento endógeno genuíno e nem reduzir a disparidade que separa os países pobres e em desenvolvimento dos países desenvolvidos sem uma educação superior e sem instituições de pesquisa adequadas que formem a massa crítica de pessoas qualificadas e cultas".

\footnotetext{
${ }^{9}$ A declaração também estabelece uma série de recomendações às Instituições de Educação Superior, a outras mantenedoras e aos governos. Mais de 30 Instituições de Educação Superior no mundo todo endossaram o documento.

${ }^{10}$ Os textos podem ser encontrados no site da UNESCO.
} 
Poderíamos inferir então, que a transferência de conhecimento, inovações tecnológicas e troca de informações que a liberalização poderia promover, seria um ponto positivo a favor da abertura do mercado de educação superior.

Dados colhidos por esta Organização internacional apontam, por outro lado, que o desenvolvimento econômico impulsionado pelas descobertas científicas feitas nos últimos 25 anos, mesmo contribuindo para que vários países emergissem do status de subdesenvolvidos para países em desenvolvimento, não podia ser visto como a maneira ideal de conciliar progresso material e acesso aos recursos naturais com igualdade e respeito à condição humana (DELORS, 1996 p. 13).

Os países em desenvolvimento não podem desconsiderar a necessidade de ingresso no mundo da ciência e tecnologia com todas as implicações em termos de adaptação cultural e modernização de mentalidades, mas é imprescindível que se estipulem meios para que as formas de cooperação não se tornem instrumentos de exclusão social.

\section{Aspectos a serem considerados sobre a liberalização do setor educacional no Brasil}

Após termos discorrido sobre a atratividade do mercado de serviços educacionais, sobre as expectativas e objetivos da educação e sobre as preocupações quanto à sua liberalização cabe agora analisarmos alguns pontos para tirarmos proveito dessa iniciativa. Entre os pontos que consideramos mais relevantes, destacam-se a capacidade de investimento tanto do setor público quanto do privado para atingir os objetivos da educação, a produtividade do setor educacional no Brasil, a escolha sobre o conteúdo programático dos cursos, as implicações da possibilidade de oferta de um serviço público por empresas estrangeiras e, finalmente, as restrições impostas pelos Conselhos que regulam o exercício das profissões.

\subsection{A capacidade de investimento público e privado para atingir melhores índices de educação no Brasil}

A inclusão educativa depende não somente da mobilização de meios físicos, mas também de outros fatores como o emprego de grades curriculares mais 
eficientes, modernização dos modelos pedagógicos, ferramentas sociais para inibir a evasão escolar, treinamento e adequada remuneração de professores, aplicação intensiva de meios cibernéticos, dentre outros (OLIVETO, 2008b), que custam dinheiro!

Conforme pesquisa conduzida com 34 países pela Organização para a Cooperação e Desenvolvimento Econômico (OCDE), o Brasil é o que apresenta menor investimento por aluno. Há oito anos o Brasil investe apenas os mesmos $4 \%$ do PIB na área de educação, isto é, R 5 bilhões. Segundo o Ministro da Educação, Fernando Haddad (OLIVETO, 2008b), o mínimo deveria ser 6\%. Para se ter uma ideia da gravidade da falta de investimento público na educação, o Brasil gasta $\mathrm{R} \$$ 120 por mês com cada estudante, quase 10 vezes menos que os gastos mensais com um presidiário ${ }^{11}$.

Os investimentos exigidos para atender à demanda crescente no campo da educação, principalmente a superior são consideráveis e cada vez menos o governo pode redistribuir as receitas da União para oferecer educação superior nos níveis necessários. Dessa forma, a atuação do setor privado nesse campo tem aumentado consideravelmente, o que contribui para reduzir o ônus das despesas do setor público e garantir que uma proporção dos custos envolvidos na prestação do serviço seja atribuída aos que se beneficiam diretamente dele.

Em termos comparativos, enquanto o investimento público em educação superior foi de 209 milhões no ano de 2002, o setor privado alavancou $764 \mathrm{mi}$ lhões em 1998 e 1.460 milhões em 2002. Além disso, o número de IES privadas no Brasil aumentou de 746, em 1998 para 1.460, em 2002, aumentando a população estudantil, variando de 2.125.950, em 1998 para 3.370.000, em 2002. Com base nesses dados, inegável a contribuição das IES privadas para atender à demanda da população em relação à educação superior.

Por outro lado, a Lei de Diretrizes e Bases da Educação Nacional de 1996, determinou que a União elaborasse um Plano, em colaboração com os Estados, o Distrito Federal e os Municípios, com diretrizes e metas para os dez

\footnotetext{
${ }^{11}$ Custos médios anuais por estudante por país, conforme dados da OCDE de 2001: US\$280 em Camarões, US\$570 na Romênia, US\$600 na Líbia, US\$670 na Federação Russa, US $\$ 785$ na Turquia e US\$1.495 no Senegal, subindo bem acima de US\$12.000 nos países industrializados (ex: US\$13.224 na Suécia).
} 
anos posteriores, em sintonia com a Declaração Mundial sobre Educação para Todos, mas admite que os "recursos financeiros são limitados e que a capacidade para responder ao desafio de oferecer uma educação compatível, na extensão e na qualidade, à dos países desenvolvidos precisa ser construída constante e progressivamente". Dessa forma, estabelece prioridades para os investimentos.

No ano passado, foi também lançado pelo Ministro Haddad, o Plano de Desenvolvimento da Educação (PDE), avaliado pela Unesco como sendo um meio em sintonia com os objetivos a serem alcançados até 2022. No entanto, o próprio ministro admite que as metas só serão alcançadas se mais investimentos forem feitos no setor.

\subsection{A produtividade do setor educacional no Brasil}

Dados da OCDE indicam que os investimentos em educação realizados pelos países desenvolvidos entre 1995 e 2001, em regra, aumentaram (CZINKOTA, 2005, p. 7). ${ }^{12}$ Em 1998, os níveis médios de despesa por estudante nos países da OCDE eram de US\$3.915 para a educação primária e de US\$11.720 para a terciária. No entanto, a qualidade do ensino não acompanhou a tendência, isto é, em termos de produtividade (fazer mais e melhor com menor custo), os ganhos foram poucos.

No caso do Brasil, a situação não é diferente. O Instituto Brasileiro de Geografia e Estatística (IBGE) divulgou recentemente dados reveladores sobre a qualidade da educação no Brasil. Sua Pesquisa Nacional por Amostra Domiciliar (PNAD) esclarece que 14 milhões de crianças e adolescentes até 17 anos estão excluídos do sistema educacional brasileiro. Os números parecem positivos quando indicam que $97 \%$ das crianças entre 7 e 14 anos estão matriculados em escolas. Mas os números também demonstram que somente $70 \%$ desses alunos terminam

\footnotetext{
${ }^{12}$ Austrália aumentou o investimento por aluno em 4\%, Hungria em 8\%, Noruega 6\% e Reino Unido em 4\%. Em outros países, no entanto, caiu. Por exemplo: a Áustria reportou uma queda de $9 \%$, a Dinamarca de $24 \%$, a França de $13 \%$, a Alemanha de $11 \%$, a Itália de $20 \%$ e a Espanha de $33 \%$.
} 
o ensino fundamental e com atraso médio de 4 anos. Os dados do ENEM também demonstram que a aquisição do conhecimento deixa ainda a desejar ${ }^{13}$ (WERTHEIN, 2008).

Em paralelo aos dados acima, os indicadores do Ministério da Educação demonstram que o desempenho das escolas da rede privada é mais elevado que os das escolas públicas (OLIVETO, 2008a). Ora, se os recursos provenientes do setor privado e a competitividade acabam por contribuir para o bem público, na medida em que trazem benefícios para a sociedade, proporcionando resultados no campo da educação superior, não há porque restringir o acesso a esse mercado ao setor privado internacional. A concorrência, nesse caso, poderia trazer benefícios quanto à inovação nas formas de ensinar e poderia aumentar as chances e a velocidade da transferência de conhecimento e recursos através das fronteiras (CZINKOTA, 2005, p. 6-9).

\subsection{A escolha sobre o que ensinar}

As leis de Diretrizes e Bases da Educação Nacional anteriores fixavam regras mais rígidas para a determinação do currículo mínimo e da duração dos cursos universitários. No entanto, a nova LDB de 1996 eliminou ou reduziu essas exigências, estabelecendo apenas diretrizes gerais para os currículos de cursos e programas de educação superior e ampliação da duração mínima do ano letivo regular, de 180 para 200 dias. Dessa forma, a nova LDB abriu perspectivas amplas para que as Instituições de Educação Superior (IES) pudessem organizar seus cursos como

\footnotetext{
${ }^{13}$ Apenas complementando esses dados, acredito que uma das principais causas desses resultados é o fato de que, no Brasil, a formação dos professores é extremamente deficitária. Nas primeiras séries do ensino fundamental, 47,3\% não têm habilitação em nível superior. $\mathrm{Na}$ Finlândia, onde o ensino é considerado um dos melhores do mundo, os professores são recrutados entre os melhores alunos das Universidades.
} 
lhes aprouvesse ${ }^{14}$. A ideia era a de que as IES pudessem definir os currículos de seus próprios cursos em lugar do sistema de currículos mínimos, propondo em linhas gerais, a definição das competências e habilidades que se desejariam desenvolver ${ }^{15}$. Em regra, essa possibilidade caberia também às empresas estrangeiras que operassem no Brasil.

O Conselho Nacional de Educação ${ }^{16}$ explica que "tais medidas inseriam-se em espírito mais amplo de proposta de reestruturação do sistema de ensino superior no país, com menor ênfase na centralização, e em prol de maior autonomia para que as instituições pudessem inovar, atendendo às demandas regionais e nacionais.”

No entanto, um dos principais pressupostos da atividade empresarial é o lucro. Então, como garantir que a forma e o conteúdo que serão ensinados irão realizar os objetivos da educação almejados pela legislação se o poder soberano de decidir sobre ações que visam a formar profissionais e cidadãos conscientes e responsáveis foi deslocado do Estado para as IES? Como a nova LDB possibilitou o aparecimento de várias instituições, muitas vezes de qualidade duvidosa e que aproveitaram a oportunidade e impuseram a esse movimento uma abordagem comercial, o alcance dos objetivos da educação superior poderia ficar prejudicado.

\footnotetext{
${ }^{14}$ Art. $53^{\circ}$. No exercício de sua autonomia, são asseguradas às universidades, sem prejuízo de outras, as seguintes atribuições:

II - fixar os currículos dos seus cursos e programas, observadas as diretrizes gerais pertinentes;

III - estabelecer planos, programas e projetos de pesquisa científica, produção artística e atividades de extensão;

Parágrafo único. Para garantir a autonomia didático-científica das universidades, caberá aos seus colegiados de ensino e pesquisa decidir, dentro dos recursos orçamentários disponíveis, sobre:

III - elaboração da programação dos cursos;

${ }^{15}$ Essa proposta se encontra em sintonia com o Processo Bolonha, no âmbito da Comunidade Europeia, que visa a uma reestruturação na graduação e pós-graduação, estabelecendo um sistema de créditos comum (ECTS) e a promoção de maior mobilidade estudantil pela remoção de obstáculos e posterior reconhecimento de títulos, dentre outros. Buscase também uma mudança do paradigma do ensino teórico em um determinado campo do conhecimento para a formação profissional para o desenvolvimento de capacidades que preparem os estudantes a serem melhores como cidadãos e membros da sociedade. O Processo iniciou sua expansão para a América Latina em cooperação com o Projeto Alfa da Comissão Europeia em março de 2005. Para mais informações vide Loussia, 2006.

${ }^{16}$ Parecer CNE/CES n. 8/2007 publicado no DOU em 13/06/2007.
} 
Sendo assim, a jurisprudência do Superior Tribunal de Justiça estipulou um limite a essa liberdade. O STJ reconheceu que o princípio da autonomia universitária "não despreza a vigilância do poder estatal da União de tornar efetivas as normas gerais da educação nacional, objetivando a prevalência da ordenação de caráter federativo, evitando a instalação de cursos órfãos de garantias do padrão de qualidade e eficiência” (STJ, CC 13758, de 7/8/1995, Rel. Min. Milton Luiz Pereira)

Além disso, é importante lembrar que o processo de liberalização da educação superior não implica em deixar que esse setor seja livremente regulado pelas forças e regras do mercado. Esse processo, devidamente implantado com a supervisão estatal, pode significar em uma melhor educação superior, disponível a mais pessoas e trazendo benefícios para o desenvolvimento sustentável de todos os países.

\subsection{A oferta de um serviço público por empresas estrangeiras}

Para muitos, o problema da liberdade acadêmica das instituições superiores é que elas se comportam como um quarto poder "um pilar independente da sociedade, crucial para o progresso e a inovação enquanto guardiãs do pensamento do passado" (CZINKOTA, 2005). O poder de ensinar e transmitir conhecimento formando o pensamento da elite profissional de um país é uma das características fundamentais que distinguem as IES das demais atividades econômicas. Dessa forma, esse seria um poder relacionado à defesa nacional que estaríamos conferindo a não nacionais com a liberalização.

Nossa Constituição de 1988 estabeleceu algumas restrições para a atuação de pessoas jurídicas de capital majoritariamente estrangeiro em alguns casos, como por exemplo, o exercício de atividades de jornalismo ou radiodifusão sonora 
e de imagens ${ }^{17}$. O legislador quis evitar que a gestão dessas atividades, a escolha do conteúdo da programação e a responsabilidade editorial nas respectivas empresas, ficassem nas mãos de estrangeiros, dado o poder de formação de opinião que essas empresas exercem ${ }^{18}$.

Ora, o mesmo poder de formar opiniões possuem as Instituições de Ensino, além de serem as responsáveis pela escolha do que deve ser aprendido e a forma. No entanto, em nossa legislação não há nenhuma restrição quanto à composição do capital de uma empresa de ensino. Dessa forma, mister se faz atribuir ao Estado o poder de controle dessa atividade no que tange à liberdade de atuação das IES mencionada no tópico acima.

${ }^{17}$ Art. 222, CF/88: "A propriedade de empresa jornalística e de radiodifusão sonora e de sons e imagens é privativa de brasileiros natos ou naturalizados há mais de dez anos, ou de pessoas jurídicas constituídas sob as leis brasileiras e que tenham sede no País. (Redação dada pela Emenda Constitucional no 36 , de 2002)

$\$ 1^{\circ}$ Em qualquer caso, pelo menos setenta por cento do capital total e do capital votante das empresas jornalísticas e de radiodifusão sonora e de sons e imagens deverá pertencer, direta ou indiretamente, a brasileiros natos ou naturalizados há mais de dez anos, que exercerão obrigatoriamente a gestão das atividades e estabelecerão o conteúdo da programação. (Redação dada pela Emenda Constitucional no 36, de 2002)

$\$ 2^{\circ}$ A responsabilidade editorial e as atividades de seleção e direção da programação veiculada são privativas de brasileiros natos ou naturalizados há mais de dez anos, em qualquer meio de comunicação social. (Redação dada pela Emenda Constitucional n 36, de 2002)

$\S 3^{\circ}$ Os meios de comunicação social eletrônica, independentemente da tecnologia utilizada para a prestação do serviço, deverão observar os princípios enunciados no art. 221, na forma de lei específica, que também garantirá a prioridade de profissionais brasileiros na execução de produções nacionais. (Incluído pela Emenda Constitucional no 36 , de 2002).

$\$ 4^{\circ}$ Lei disciplinará a participação de capital estrangeiro nas empresas de que trata o $\$ 1^{\circ}$. (Incluído pela Emenda Constitucional no 36 , de 2002).

$\S 5^{\circ}$ As alterações de controle societário das empresas de que trata o $₫ 1^{\circ}$ serão comunicadas ao Congresso Nacional. (Incluído pela Emenda Constitucional no 36, de 2002)”.

${ }^{18}$ Essa posição pode ser fundamentada conforme escreveu Carmen Tibúrcio (2002): “ [...] a regra geral de igualdade (dos estrangeiros) não se aplica aos chamados direitos econômicos - que, de resto, não são considerados fundamentais, por boa parte dos operadores jurídicos. Segundo o Pacto Internacional dos Direitos Econômicos, Sociais e Culturais, em vigor no Brasil, os países em desenvolvimento, levando em consideração os direitos humanos e a situação econômica nacional, poderão determinar em que medida garantirão os direitos econômicos reconhecidos no Pacto àqueles que não sejam seus nacionais. Isto é: nessa área específica, o estrangeiro pode receber tratamento diferente do nacional, mesmo que não haja uma razão expressa para isto, e o Estado não precisa justificar tal atitude na esfera internacional." 


\subsection{0 exercício das profissões}

Outro limite colocado à liberdade conferida às IES quanto à escolha do conteúdo a ser ensinado e a forma de prestação do serviço é o fato de que, para o exercício das profissões, é necessário o diploma conferido pelas IES e, para tal, os Conselhos de Ordens das profissões regulamentadas por lei exigem uma rigidez normativa que conflita com essa liberdade auferida pelas IES.

Segundo a jurisprudência do STJ, compete aos Conselhos de Ordem atuar no sentido de estabelecer a preservação da qualidade dos cursos que formam seus profissionais por meio da análise do programa, da qualidade e do currículo dos cursos, opinando quando da criação, extinção e alterações de importância nas diretrizes curriculares. No Mandado de Segurança MS 8592 / DF, declarou que ao Estado não é lícito criar normas vagas que confiram às instituições de ensino tamanha liberdade na definição do currículo do curso, em desrespeito à qualidade da educação exigida pela própria Constituição Federal como se segue:

Compete à $\mathrm{OAB}$ a aferição da capacidade para o exercício profissional da advocacia, atribuição que lhe é conferida pelo artigo $8^{\circ}$, inciso I, da Lei n. 8.906/94, aspecto que reforça, sobremaneira, seu interesse na preservação de qualidade mínima para o desempenho do mister, sem o perigo de péssimos profissionais, por deficiente formação acadêmica, colocarem em risco a defesa de direitos, seja na advocacia contenciosa seja na consultoria preventiva. Não se deve perder de vista, também, que a função do advogado, consoante a Constituição Federal (artigo 133), é indispensável à administração da justiça.

A análise quanto ao programa, a qualidade e o currículo dos cursos de Direito deve ficar a cargo da OAB, entidade que, apesar de não ter poder de veto, tem participação fundamental no processo de melhoria do ensino jurídico no Brasil. Destarte, a OAB deve opinar não apenas quando da criação ou extinção de cursos jurídicos, mas também quando ocorrerem alterações de suma importância nas diretrizes curriculares, como na hipótese em exame.

Ao Estado não é lícito criar normas vagas que confiram às instituições de ensino jurídico tamanha liberdade na definição do currículo do curso, em desrespeito à qualidade da educação exigida pela própria Constituição Federal.

A abertura de faculdades de Direito como está sendo realizada no Brasil nos últimos anos, longe de democratizar 
o ensino, prejudica sua qualidade. Observa-se que, conforme cresce o número de vagas nos cursos de Direito, diminui a qualidade do ensino. A adoção do Parecer n. 146/2002 vem a colaborar para a expansão de novos cursos jurídicos deficientes no país.

Diante desse quadro, jamais se poderia pensar em implementar sistema de redução da carga horária do curso de Direito e conferir ampla autonomia às instituições de ensino na fixação do currículo dos cursos jurídicos, mas sim em reforçar o controle sobre as instituições de ensino, sobretudo as privadas, - cujo interesse econômico no aumento do número de vagas supera, em muito, o interesse meramente educativo -, e, até mesmo, ampliar o número de anos para a conclusão do curso.

Dessa forma, cabe ao Conselho Nacional de Educação (CNE) conciliar a flexibilidade da prestação educacional, a rigidez normativa das corporações e a natureza formal da CLT. A diversidade de ofertas e duração dos cursos superiores e de graduação encontra limites nas regras para o acesso à licença profissional. Podem-se verificar inúmeras manifestações das Ordens, vedando a prática profissional de egressos do ensino superior diplomados segundo critérios de duração e concepção de cursos não endossados pelas corporações. ${ }^{19}$

Então, diferentemente da doutrina da LDB e da vontade do legislador de conferir liberdade às IES quanto à escolha do currículo mínimo e da duração dos cursos, as corporações, ao estipularem a uniformidade e o caráter nacional de formação dos profissionais, erigiram limites à autonomia das IES e, por conseguinte, conferiram uma identidade corporativa nacional indivisível ao ensino das profissões.

Importante ressaltar que, no caso da liberalização, muitos países trabalham para uma uniformização do currículo dos cursos a fim de garantir às IES nacionais e estrangeiras a igualdade na atuação e, consequentemente, a possibilidade de conferir titulações para a prática das profissões. A liberdade conferida pela LDB às IES referente à escolha do currículo mínimo dos cursos superiores atenderia esta demanda. Por outro lado, os Conselhos atuam para a proteção da manutenção da qualidade do ensino na formação de nossos profissionais.

\footnotetext{
${ }^{19}$ Parecer CNE/CES n. 8/2007.
} 


\section{Conclusão}

Vários Estados argumentaram em favor da extensão do GATS à educação e, mais especificamente, à educação superior. $\mathrm{O}$ Acordo tem recebido diferentes reações e, sem dúvida, afetará de várias maneiras os países signatários. Mas, assim como a globalização, o comércio no campo da educação superior é uma realidade e um caminho sem volta.

No entanto, há um consenso generalizado de que a educação superior não pode ser comercializada como uma mercadoria qualquer. Os Estados, governos e as próprias instituições não devem perder de vista o fato de que estão lidando com um bem público geral que, consequentemente, não pode ficar à mercê das regras de mercado.

Por outro lado, a liberalização do mercado de educação é uma iniciativa que pode incrementar os investimentos privados para o setor muito carente de recursos públicos. Esses investimentos não são apenas materiais, mas também incluem inovações pedagógicas e tecnológicas. No entanto, cabe lembrar que apenas investimentos não acarretarão na melhoria da educação. Muito pelo contrário. Se regras bem definidas não forem estabelecidas, estaremos entregando a formação de nossos futuros profissionais aos interesses privados, nem sempre afinados com os ideais de igualdade, inclusão social e desenvolvimento que devem ser alcançados por meio da educação. Dessa forma, a regulamentação do setor se faz necessária para garantir a qualidade e a disponibilidade do acesso da população às oportunidades educacionais.

Parafraseando o Relatório da UNESCO, vale ressaltar que a "Educação não é mágica ou milagre contra exclusão social, guerra, ignorância ou opressão, mas um instrumento de combate e um direito do indivíduo" (DELORS, 1996, p. 11). Isso deve ser levado em conta quando as escolhas políticas, econômicas e financeiras forem feitas. 


\section{High education in Brazil and the market liberalization proposed by GATS}

\section{Abstract}

Due to the great attractiveness of the International Market of Education, the market liberalization promoted by the GATS is already a reality. However, there is still a strong resistance from some countries that consider Education a public service and must be regulated by the State. The same reasoning is shared by Academia that believes that Education is of high importance to promote the social objectives necessary to the construction of a Nation and therefore should not be regulated by the market rules. It is then, imperative to discuss how to achieve sustainable development through new ways of international cooperation in order to avoid social exclusion. The text points some relevant aspects to be considered when the market is opened.

Keywords: Liberalization. Commerce. Education. GATS. Sustainable development.

\section{Referências}

BELLONI, Isaura. A educação superior na nova LDB. In: BRZEZINSKI, Iria (Org.). LDB Interpretada: diversos olhares se entrecruzam. São Paulo: Cortez, 1998.

BRASIL. Constituição (1988). Constituição da República Federativa do Brasil. São Paulo: Revista dos Tribunais, 2003.

BRASIL. Lei $n^{\circ}$ 9.394, de 20 de dezembro de 1996. Estabelece as diretrizes e bases da educação nacional. Disponível em: < http://www.planalto.gov.br/ccivil_03/LEIS/ 19394.htm>. Acesso em: 25 jun. 2009.

BRASIL. Ministério do Desenvolvimento, Indústria e Comércio Exterior. SECEX. Brasília, 2008. Disponível em: <http://www.desenvolvimento.gov.br>. Acesso em: 27 abr. 2008.

BRASIL. Ministério da Educação. Conselho Nacional de Educação. Câmara de Educação Superior. Parecer CNE/CNS n.8/2007. Brasília, 2007.

CONDON, Bradly J. NAFTA, WTO and global business strategy: how aids, trade and terrorism affect our economic future. Londres: Quorum Books, 2002. 
CZINKOTA, Michael R. Prepared statement for the world trade organization. Symposium on cross-border supply of services. Genebra: Abril. 2005.

DELORS, Jaques. Aprendizado, o tesouro interior. Paris: UNESCO, 1996. Relatório apresentado à UNESCO.

DIAS, Marco Antônio. Educação superior: bem público ou serviço comercial regulamentado pela OMC? In: REUNIÃO DE REITORES DE UNIVERSIDADES PÚBLICAS ÍBERO-AMERICANAS, 2002, Porto Alegre. Anais... Porto Alegre: [s.n.], 2002.

EDUCAÇÃO superior: reforma, mudança e internacionalização. Anais. Brasília: UNESCO, 2003. Disponível em: <http://unesdoc.unesco.org/ images/0013/001339/133972por.pdf\#xml=http://unesdoc.unesco.org/ulis/cgibin/ ulis.pl?database $=\& s e t=482 F 37 D 6 \_0 \_115 \&$ hits_rec $=2 \&$ hits_lng=por $>$. Acesso em: 15 maio 2008.

FELIX, Loussia P. Musse. O projeto Alfa Tuning e a área de direito: competências como eixo da formação na perspectiva latino-americana. Brasília: Universidade de Brasília, 2006. Notícia do Direito Brasileiro. (Nova série, n. 13).

GATS: World Trade Organization. Services trade. Geneva, 2008. Disponível em: <http://www.wto.org/english/tratop_e/serv_e/serv_e.htm>. Acesso em: 10 maio 2008.

JOSPIN, Lionel. Cérémonie d’ouverture. In: CONFÉRENCE MONDIALE SUR L'ENSEIGNEMENT SUPÉRIEUR, 1998, Paris. Anais... Disponível em: <www. unesco.org>. Acesso em: 25 jun. 2009.

OLIVETO, Paloma. Aprender de verdade. Correio Braziliense, Brasília, p. 8, 18 mar. 2008a.

OLIVETO, Paloma. Dinheiro bem aplicado. Correio Braziliense, Brasília, p. 8, 20 mar. 2008b.

ORGANIZATION FOR ECONOMIC CO-OPERATION AND DEVELOPMENT. [Home Page]. Paris, 2008. Disponível em: <www.oecd.org>. Acesso em: 12 maio 2008.

RANIERI, Nina Beatriz Stocco. Internacionalização da educação superior. Revista Estudos da Associação Brasileira de Mantenedoras de Ensino Superior, Brasília, v. 22, n. 33, p. 29-48, 2004. 
108 Univ. Rel. Int., Brasília, v. 6, n. 2, p. 89-108, jul./dez. 2008

SAINT-PIERRE, Celine. Céremonie de clôture. In: CONFÉRENCE MONDIALE SUR L'ENSEIGNEMENT SUPÉRIEUR, 1998, Paris. Anais... Disponível em: <www.unesco.org>. Acesso em: 25 jun. 2009.

TIBÚRCIO, Carmen. A participação de estrangeiros na mídia. Jornal do Comércio, Rio de Janeiro, p. A-16, 2003.

TIBÚRCIO, Carmen. Participação de estrangeiros na mídia. Boletim de Direito Internacional, [S.1], n. 33, outubro de 2002.

UNESCO. [Home page]. Paris, 2008. Disponível em: <http://portal.unesco. org/education/en/ev.php-URL_ID $=48712 \&$ URL_DO=DO_TOPIC\&URL_ SECTION=201.html $>$. Acesso em: 12 jun. 2008.

WERTHEIN, Jorge. A urgência da educação. Correio Braziliense, Brasília, p. 13-14 abr. 2008. 